\title{
Challenges of additive manufacturing in production systems
}

\author{
Angela Luft ${ }^{1, *}$, Andreas Gebhardt ${ }^{1}$, and Nicolae Balc ${ }^{2}$ \\ ${ }^{1}$ FH Aachen University of Applied Sciences, Department of Mechanical Engineering and \\ Mechatronics, Goethestr. 1, 52064 Aachen, Germany \\ ${ }^{2}$ Technical University of Cluj-Napoca, Department of Manufacturing Engineering, B-dul Muncii 103- \\ 105, 400641 Cluj-Napoca, Romania
}

\begin{abstract}
Additive Manufacturing (AM) has become indispensable in the context of digitalization and Industry 4.0 and is said to be a mega trend of the 21 st century. The technology offers immense opportunities to revolutionize the production of parts and components in all industries. Despite of the outstanding technical possibilities, the industry-wide adaptation rate is low. The current approach of looking at AM from a mostly technological view is a major reason for this. The challenge is to efficiently integrate $3 \mathrm{D}$ printing and other additive processes into existing manufacturing processes and systems. AM must be perceived as a multidimensional topic and viewed from different perspectives, two of which are the AM technology and the planning and management of production systems. These two perspectives have to be addressed simultaneously and cross-linked. In order to use AM to tackle some of the most challenging problems in modern manufacturing systems like increasing variant diversity, shorter product lifecycles, the demand for digitized processes and cyber-physical systems, it is necessary to develop interdisciplinary approaches and solutions, because none of the disciplines can reach the necessary performance and cost-efficiency alone.
\end{abstract}

\section{Initial situation and problem definition}

The flexibility and changeability of production systems are still becoming more and more important. Nowadays, amongst other developments companies have to deal with shorter product lifecycles, the customization/ individualization of their products as well as more product diversity and variants and thereby greater external and internal variance that lead to decreasing batch sizes and obliterate most long-term forecasts [1-3]. Through globalization and global interconnection, competitive pressure and the need to increase efficiency and effectiveness are growing even stronger. Another megatrend that came up during the last years is the topic of Industry 4.0 and Digitization. CPS (cyber-physical systems), Sensitive Robotic, Smart Automation, Big Data and Predictive Analytics, Additive Manufacturing, Cloud Computing (XaaS) and Advanced Assistance Systems are some of the most important technologies that came up production-sided in this context [4].

\footnotetext{
* Corresponding author: a.luft@,fh-aachen.de
} 
Companies need to deal with these developments by becoming more performant and efficient and by reacting highly flexible. In this regard, the production systems have to hold more and more options to shift volume on short notice and with little to no time to react. So, it is tremendously important for companies to decide wisely which technologies to implement and when and how they proceed. However, this is extremely difficult and challenging, since many of the technologies are subject to strong interactions, partly build on each other and also currently having very different maturity levels. Furthermore, there are almost no standards that companies can fall back on regarding many of these technologies, nor is a valid number of successful showcases available as references.

All these developments and circumstances make clear that the concept of flexibility is a key factor for handling today's challenges of companies respectively their production systems. In this regard, a central question at this point is how to increase the flexibility in production systems quickly and on short notice.

\section{Current development in the Industry}

The reaction of the industry to these challenges can be seen in the latest developments. One major concept designed to improve production systems and make them more flexible is Industry 4.0. Through intelligent networking of machines and processes in the industry with the help of information and communication technologies, Industry 4.0 aims to produce more individualized products by achieving a higher degree of flexibility in production systems [4]. This also corresponds to the answers given by German companies to the question of why they invest in Industry 4.0 technologies, which indicate a more flexible response to changing requirements, faster adaptation to fluctuations in demand and increased efficiency as their top 3 reasons (see Fig. 1) [5].

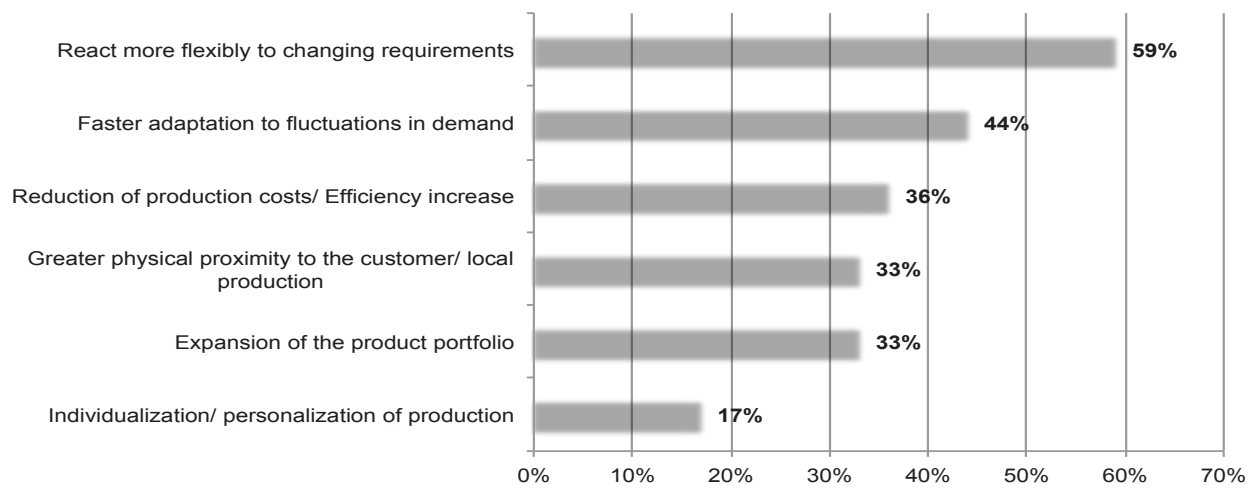

Fig. 1 Why German companies invest in Industry 4.0 technologies (as of 2018) [5]

Most of the companies asked during these surveys want to use digital technologies like Cloud Computing, Smart Services or the Internet of Things for automation purposes with the long-term goal of the automation of their production processes and systems. This will, in the end, lead to much more flexible production systems [5]. However, companies still also have to deal with challenges along the way towards a digital factory. Especially high investment costs, steep requirements when it comes to data security and data protection as well as the potential error rate of manufacturing systems that operate largely unchecked by humans and other external intelligence. These challenges are reinforced by the current lack of qualified employees as well as the sheer complexity of the development (see Fig. 2) [5]. Due to the fact that many of these technologies have varying degrees of maturity and are very interconnected the question of where to start and what technology to use in order to 
tackle a specific problem is very hard to answer. Even though the long-term benefits of digitally enhanced and more flexible production systems are undisputed, there are many questions unanswered when it comes to roadmaps towards Industry 4.0 and the composition of the flexibility-constituting elements within the manufacturing systems.

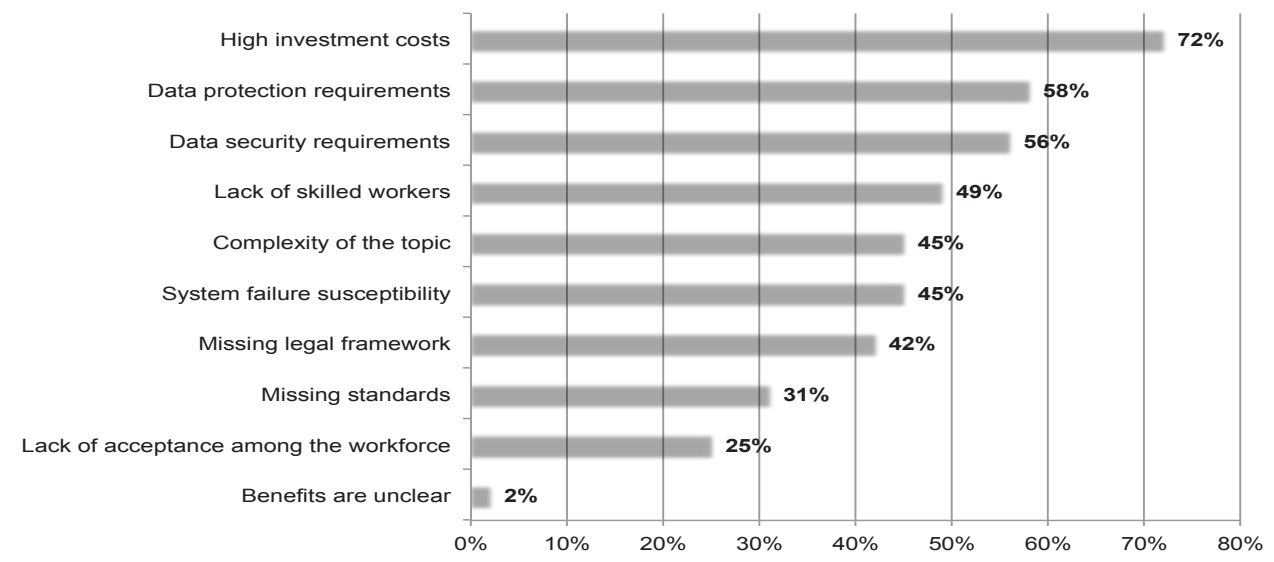

Fig. 2 What obstacles German companies see in the use of Industry 4.0 (as of 2018) [6]

With these challenges looming large, especially small and medium-sized manufacturing companies are trying to find ways to implement more flexibility on short notice in order to tackle the increasing variance and buy some time for other technologies to reach a higher maturity level. In this context, the technology of Additive Manufacturing is receiving more and more attention due to its unique characteristics and potentials when it comes to the manufacturing of small quantities of products or components. Moreover, the versatility of the technology in terms of functional integration (and thus process chain optimization) and the manufacturing of different components in one run promises a substantial but rather costeffective boost of production system flexibility due to the enhanced machine flexibility $[7,8]$.

The relevance for AM in the industry is also shown by the rapidly growing market. According to the American research company SmarTech Publishing the market in 2018 grew by $18 \%$ compared to 2017 . In 2018, the sector generated 9,3 billion dollars (sales include the areas hardware, materials, services, and software.) SmarTech even expects the market to exceed 41 billion dollars by 2027 . The growth can be explained with two trends: on the one hand the adaption of the technology by large companies (global players) that want to speed up product development times and want to push the use. Secondly, to connect AM technologies with existing tooling machines to enable more complex and diverse applications [9].

In conclusion, it can be argued that companies want to use available Industry 4.0 technologies to realize the goal of a more flexible digitized production. However, since there is currently no generally accepted path towards an industry 4.0 level manufacturing system and the required technologies have substantially different technical readiness levels (TRL) Additive Manufacturing at this point shows the greatest potential to tackle the challenges mentioned above and solve companies short term need for more manufacturing flexibility.

\section{Flexibility in Production Systems}

Although there are still many obstacles for companies on their way to more flexibility in their Production Systems, the concept of flexibility has already a more than eight-decade long history $[7,10]$. In general, flexibility can be understood as the ability of a system to handle change without necessarily changing its internal structure or resources. At the end of 
the 1980ies, other concepts like changeability or adaptability started to rise [11-15]. Since approx. 2010 the demand for more flexible production systems rose again due to an explosion of the number of product options and variant varieties. As an example, the potential options list for the customers of car makers exceeded millions of buildable combinations and billions of options [16]. This explosion of options combined with shorter product lifecycles and smarter products puts enormous stress on manufacturing systems. As a direct result of these developments production systems have to deal with highly increased numbers of parts and therefore processes, much smaller batch-sizes, and substantially worse forecasting. The general answer to this development is production systems with a much higher degree of flexibility.

It can be said, that different technical aspects of Additive Manufacturing, as well as flexible production systems, have been investigated separately in the literature, but they have not been joined together. Very little research has been conducted so far to close the gap between AM and flexible production systems. Also, in practice, companies (especially SME) still struggle to react to increasing product complexity and to streamline their production processes and related fields (e.g. logistics and administration). In this context, AM could help to create more flexible and cost-effective production systems within versatile structures.

Summarizing, AM allows widening the flexibility corridor for different products and variants with various process chains and the respective manufacturing processes. In contrast to existing flexibility theories, this can happen without requiring back-up resources for the individual procedures/ manufacturing steps.

\section{Application potentials and challenges of Additive Manufacturing}

This idea is supported by the fact that Additive Manufacturing processes as well as the machines itself are very flexible and can be -apart from economic efficiency- technically used to print almost any kind of product [17].

Based on the technical advantages of Additive Manufacturing, the following potentials can emerge when transferring AM systematically to the concept of increased flexibility of production systems:

- Short-term flexibility is possible by installing 3D-printers in the right place

- Relatively low investment costs (compared to full digitization)

- Easy scalability (by adding more 3D-Printers)

- Short implementation times

- Existing ecosystems as extended workbench (option of outsourcing becomes very simple)

- Reduction of complexity in components through functional integration (printing internal structures and fully assembled units instead of single components to be assembled)

- More complex and diverse applications

Besides these positive prospects and potentials of AM, lots of challenges in the practical use of AM in the industry still exist. The following points are a summary of today's most important obstacles before AM can be successfully implemented into production systems [18,19]:

- Qualification of components (often a major Showstopper for companies)

- Lack of expertise concerning the technology

- Integration of 3D-printers into existing conventional manufacturing systems (e.g. vibrations, temperature, media supply)

- AM machines not fully ready for series production

- Missing work safety regulations (e.g. for working with powder materials)

- Missing quality assurance processes 
- Missing ability to connect AM processes to build up a process chain

- Challenges in program planning

- No ERP and MES interfaces taken into account (and therefore AM machines cannot be integrated into the production line)

- Integration into overall production system and process automation not yet possible

- Material supply often only possible via machine manufacturer (restrictions to materials and high costs)

- Due to the layer-by layer process it needs to be dealt with other material behavior (anisotropic behavior) than those with conventional machines

- Problem of trial-and-error before getting usable results (expensive failed attempts before a part is ready for being produced)

- Very limited and separated focus on either production management or technology development

The points mentioned above show both the challenges as well as the tremendous potential of AM technologies when it comes to increasing the flexibility of manufacturing systems.

\section{Research and action potential}

The current developments and the challenges arising from a constantly increasing level of complexity within production systems show the magnitude of the transformation that manufacturing companies are facing today. The reasons are increasing external and internal variance on the one hand and the risks and challenges accompanying the potential solutions technologies summarized as Industry 4.0 on the other hand. The necessity for more flexible production systems is paramount, but when it comes to the question of how to create such systems there are no best practice solutions so far. The Additive Manufacturing technologies show enormous potential in this regard, especially with the potential benefits mentioned above. In order to create such hybrid production systems in which conventional manufacturing technologies exist side-by-side with 3D-printers, many problems have to be solved and not all of them are technical.

Especially the question concerning the creation of the right kind and amount of flexibility within production systems is one that absolutely needs to be answered in advance since adding unnecessary flexibility in the form of expensive machinery into a production system will cost money, disrupts process chains and wastes resources. In order to tackle this problem, it is necessary to develop a consistent, process-oriented multi-dimensional assessment tool that will allow the integration of 3D-printers into the strategic capacity and flexibility evaluation process.

However, the analysis of the currently available flexibility assessment models and algorithms suggests, that when it comes to the integration of Additive Manufacturing into production systems, the currently available tool will not be sufficient. This can, among other things, be attributed to the following reasons:

- Only a very small number of available models are process-oriented and therefore can be used to simulate a multi-process substitution like the one represented by 3D printing.

- Many existing models only focus on specific types of flexibility and therefore cannot be used to evaluate the whole potential of Additive Manufacturing

- All models identified so far only focus on different kinds of flexibility and not on the relevant areas of stock levels, routing problems, changeover costs, and sequence problems.

- When it comes to Additive Manufacturing, most evaluation models focus on the costs per piece and leave out potential secondary gains within the production systems 
Besides these challenges that primarily have its roots within the existing models for flexibility evaluation, there are various other challenges that need to be addressed as well in order to realize the widespread application of Additive Manufacturing. Most of these challenges mentioned in section 4 are being addressed right now in many places. But the question of the strategic assessment of Additive Manufacturing in the context of the flexibilization of production systems has not been discussed adequately so far. It is however tremendously important to answer this question regarding the design of strategic flexibility with the help of 3D-printing technologies because these technologies will be a substantial factor on the way towards Industry 4.0 on the one hand and the necessary short term flexibilization of production systems on the other hand.

In order to achieve this goal, it will be necessary to constitute interdisciplinary teams. Experts for the Additive Manufacturing technology have to work hand in hand with experts for operations management and industrial engineering in order to create a multidimensional perspective of the challenges involved and derive overreaching solutions for the flexibilization of manufacturing with additive technologies.

This work was supported by a grant of Romanian Ministry of Research and Innovation UEFISCDI, project number PN-III-P1-1.2-PCCDI-2017-0224, Contract 77PCCDI/2018 within PNCDI III program.

\section{References}

1. M. Schenk, S. Wirth, Springer Vieweg Verlag, Berlin (2004)

2. E. Abele, G. Rumpel, J. Cachay, Industrie Management 26, 6 (2009)

3. E.Westkämper, , E. Zahn, Springer Verlag, Berlin Heidelberg (2009)

4. BMWi, Bundesministerium für Wirtschaft und Energie (BMWi), Berlin, (2019)

5. M. Marbler, S. Bley, EY Study: Industrie 4.0 im Deutschen Mittelstand Befragungsergebnisse 2018, Ernst \& Young GmbH, Stuttgart (2018)

6. A. Berg, Industrie 4.0 - Wo steht Deutschland?, Bitkom e.V., Berlin (2018)

7. A. Sethi, S. Sethi, Flexibility in manufacturing: A survey, Int. J. of Flexible Manufacturing Systems 2, 4 (1990)

8. N. Luft, , Verlag Praxiswissen, Dortmund (2013)

9. 3Dnatives N.N., Der globale Markt für additive Fertigung im Jahr (2018)

10. J. Shewchuck, C. Moodie, Int. J. of Flexible Manufacturing Systems 10 (1998)

11. E. Westkämper, Kontinuierliche und partizipative Fabrikplanung, wtWerkstattstechnik online, 90, 3 (2000)

12. H. P. Wiendahl, R. Hernández, V. Grienitz, Planung wandlungsfähiger Fabriken, Zeitschrift für wirtschaftlichen Fabrikbetrieb, 97, 1-2 (2002)

13. G. Schuh, J. Berlak, S. Gottschalk, A. Kampker, Design for Changeability (DCF), wtWerkstattstechnik online 94, 4 (2004)

14. K.-W. Witte, W. Vielhaber, C. Ammon, wt Werkstattstechnik online 95, 4 (2005)

15. N. Gronau, Ermittlung der, ERP Management 1, 2 (2005)

16. A. Lechner, Modellbasierter Ansatz zur Bewertung vielfaltsinduzierter Logistikkomplexität in der variantenreichen Serienfertigung der Automobilindustrie, Verlag Praxiswissen, Dortmund (2012)

17. A. Gebhardt, J. Kessler, L. Thurn, 3D Printing - Understanding Additive Manufacturing, Hanser Verlag, Munich (2019)

18. S. Käfer, Additive Fertigung - die ungelösten Probleme, Maschinenmarkt Vogel,

19. C. Feldmann, A. Gorj, 3D-Druck und Lean Production, Springer Verlag, Wiesbaden (2017) 